\title{
Comparison in the physiology results between Male and Female undergraduate medical students
}

\author{
Mohammad Uzire Azam Khan ${ }^{1}$
}

\begin{abstract}
Background: In recent years more female students than males qualify to study in medical colleges of Bangladesh. Whether female students do better than males in their course exam is not known. Objective: To compare the $1^{\text {st }}$ term physiology result between male and female undergraduate medical students. Method: This cross-sectional comparative study was conducted in the Department of Physiology, Abdul Malek Ukil Medical College, Noakhali during the period of June-August'13. One hundred and fifteen students of a selected public medical college of Bangladesh were enrolled purposively for the study. Written informed consent of students and authority was taken. Data on admission merit-score and $1^{\text {st }}$ term marks were collected. The written marks were scored out of 70 and oral out of 100. The result was classified as 'passed', 'failed' and 'absent'. The statistical analysis was done by Student's ' $t$ ' test and Chi-square test as applicable. P value $<0.05$ was significant. Result: Among the selected students male were 48 (41.74\%). The mean admission merit-score of male and female students was similar $(\mathrm{p}>0.05)$. In $1^{\text {st }}$ term exam the male and female students obtained similar marks in written ( $p>0.05)$ and in oral $(p>0.05)$. When the result was categorized as 'passed', 'failed' and 'absent', still they yielded no significant difference between male and female students' result $(\mathrm{p}>0.05)$. Conclusion: The result of male and female undergraduate medical students in the $1^{\text {st }}$ term physiology exam was similar.
\end{abstract}

Key words: Gender difference, Physiology education

J Bangladesh Soc Physiol. 2016, December; 11(2): 47-49

For Authors Affiliation, see end of text.

http://www.banglajol.info/index.php/JBSP

\section{Introduction}

$\mathbf{T}$

he research has found that the male brain is on average 10 to 15 percent larger and heavier than the female brain. Using brain mapping, it has been established that men possess on average more than six times the amount of gray matter related to general intelligence than women, while women have nearly ten times the amount of white matter related to intelligence than do men., ${ }^{1,2}$ The inferior parietal lobe of male brain is generally larger. That lobe is involved in mathematical

Received 20th April 2015; $\quad$ Accepted 11th June 2016 reasoning and skills that boys tend to perform better than girls. The left side of the brain, which is responsible for the ability to use language and connected to verbal and written ability, develops sooner in girls, and girls therefore tend to perform better than boys in those areas. ${ }^{2,3}$ So there are considerable gender-related differences in brain structure. It is known that cerebral morphological differences across gender begin in the womb, and are relatively permanent after the fetus is 26 weeks old. ${ }^{4}$ These structural differences do not seem to be affected to a significant extent by 
hormonal influences as children mature, nor by innate racial differences. ${ }^{5}$

Scientists have tried to know whether differences in brain structure have any effect on the acquisition of knowledge in different fields. Ma ${ }^{6}$ described that gender differences are negligible during the elementary grades, noticeable during the intermediate grades, and pronounced during the high school grades. ${ }^{6}$ Girls usually perform better at school leaving examinations and upper secondary school. On average, girls also achieve higher grades or passing rates in many European countries. Almost all countries are concerned about the fact that the proportion of men and women vary considerably between different areas of study in tertiary education. ${ }^{7}$ Data regarding the gender difference in the result of examinations of tertiary education in our country is scares. So this study was designed to compare the $1^{\text {st }}$ term physiology result between male and female undergraduate medical students in order to test whether the female students of medical college do better than their male counterpart in course examinations.

\section{Method}

This cross-sectional comparative study was conducted in the Department of Physiology, Abdul Malek Ukil Medical College, Noakhali during the period of June-August, 2013. One hundred and fifteen students of a selected public medical college of Bangladesh were enrolled purposively for the study. Consent of students and authority was taken. Data on admission merit-score and $1^{\text {st }}$ term marks were collected. The written marks were scored out of 70 and oral out of 100. The result was classified as 'passed', 'failed' and 'absent'. Data was analyzed by SPSS (version 16). The continuous data was compared by Student's 't' test and categorical data by Chisquare test. $\mathrm{P}$ value $<0.05$ was significant.

\section{Result}

There were 48 (41.74\%) males. The mean \pm SD admission merit-score of male and female students was similar (156.27 \pm 5.78 vs $158.39 \pm 6.40, p>0.05)$. In $1^{\text {st }}$ term exam the male and female students obtained similar marks in written $(47.25 \pm 7.15$ vs $47.89 \pm 8.15, \mathrm{p}>0.05$, $95 \% \mathrm{CI},-3.733$ to 2.442 ) and oral examinations (63.19 \pm 8.049 vs $66.36 \pm 9.13, \mathrm{p}>0.05,95 \% \mathrm{CI}$, 6.632 to.292). Among the male students $20(41.7 \%)$ passed, 22 (45.8\%) failed and $6(12.5 \%)$ were absent and among the female students $26(38.8 \%)$ passed, 34(50.7\%) failed and $7(10.7 \%)$ were absent. There was no significant difference between male and female students' results $(\mathrm{p}>0.05)$.

Table I: Comparison of marks between male and female student obtained at admission merit test and $1^{\text {st }}$ term physiology examination $(n=115)$

\begin{tabular}{lccc}
\hline Score/marks & $\begin{array}{c}\text { Male } \\
(\mathrm{n}=48)\end{array}$ & $\begin{array}{c}\text { Female } \\
(\mathrm{n}=67)\end{array}$ & $\begin{array}{c}\mathrm{p} \\
\text { value }\end{array}$ \\
$\begin{array}{l}\text { Admission } \\
\text { merit }\end{array}$ & $156.27 \pm 5.78$ & $158.39 \pm 6.40$ & $>0.05$ \\
$1^{\text {st }}$ term & $47.25 \pm 7.15$ & $47.89 \pm 8.15$ & $>0.05$ \\
exam & & & \\
\hline
\end{tabular}

Data expressed as mean \pm SD. $\mathrm{p}$ value derived from Independent sample $t$ test

Table II: Comparison of success, unsuccess and absence between male and female students in $1^{\text {st }}$ term physiology examination $(n=115)$

\begin{tabular}{lccc}
\hline Parameter & $\begin{array}{c}\text { Male } \\
(\mathrm{n}=48)\end{array}$ & $\begin{array}{c}\text { Female } \\
(\mathrm{n}=67)\end{array}$ & $\begin{array}{c}\mathrm{p} \\
\text { value }\end{array}$ \\
\hline no.(\%) & no. $(\%)$ & \\
Failed & $20(41.7 \%)$ & $26(38.8 \%)$ & $\mathrm{p}>0.05$ \\
Absent & $6(12.5 \%)$ & $7(10.7 \%)$ & \\
\hline
\end{tabular}

$\mathrm{p}$ value derived from Chi-square test

\section{Discussion}

In recent years more female students than males qualify to study in medical colleges of Bangladesh. Whether female students do better 
than males in their course exam is not known. Several countries incorporated specific gender equality provisions in legislation or in governmental strategies and some make it compulsory for higher education institutions to create their own gender equality policies. Almost all countries are concerned about the fact that the proportion of men and women vary considerably between different areas of study in tertiary education. ${ }^{7}$ Discipline physiology is not an exception in this case.

Over the past century, many countries have made significant progress in narrowing or closing longstanding gender gaps in many areas of education and employment, including educational attainment, pay and labour market participation. But new gender gaps in education are opening. Young men are significantly more likely than young women to be less engaged with school and have low skills and poor academic achievement. ${ }^{9}$ In our study we found that the result of the first term physiology examination of male and female students are equal. To compare our study findings, published data are rare in this field. However, a study related to language learning showed that female students outscored that of the males, the magnitude of the difference and strength of association was relatively small. ${ }^{8}$ Women participation is increasing at all levels of educations. Gaps in primary enrollments have closed, and in secondary and tertiary enrollments, new gaps are emerging-for boys. College enrollments increased sevenfold for women over the past three decades, fourfold for men. ${ }^{10}$

\section{Conclusion}

The result of male and female undergraduate medical students in the $1^{\text {st }}$ term physiology exam was similar.

\section{Conflict of interest None}

\section{Acknowledgement}

The author is thankful to Mr. Raquib for providing merit score.

\section{Authors affiliation}

*1. Associate Professor, Department of Physiology, Abdul Malek Ukil Medical College, Noakhali, Bangladesh. E-mail: uzire@yahoo.com. Tele +8801722110369

*for correspondence

\section{References}

1. Kaufmann C, Elbel GK, Gossl C, Putz B, Auer DP. Frequency Dependence and Gender Effects in Visual Cortical Regions Involved in Temporal Frequency Dependent Pattern Processing. Hum Brain Mapp. 2001;14 (1): 28-38.

2. Haier RJ, Jung RE, Yeo RA, Head K, Alkire MT. The neuroanatomy of general intelligence: sex matters. Neuroimage. 2005 Mar;25(1):320-7. Epub 2005 Jan 16.

3. Gabriel P and Schmitz S. Gender Differences in Occupational Distributions among Workers. Monthly Labor Review. 2007(June):19-24.

4. Achiron R, Lipitz S and Achiron A. Sex-related differences in the development of the human fetal corpus callosum: In utero ultrasonographic study. Prenatal Diagnosis. 2001;21:116-120.

5. Shors $\mathrm{T}$ and Miesegaes G. Testosterone in utero and at birth dictates how stressful experience will effect learning in adulthood. Proceedings of the National Academy of Sciences of the United States of America. 2002; 99(21):13955-13960.

6. Ma, X. Gender differences on growth in mathematical skills during secondary grades: A growth model analysis. AJER. 1999;45:448-466.

7. Eurydice network. Gender Differences in Educational Outcomes. Study on the Measures Taken and the Current Situation in Europe. [Internet].2010. Available from: http://www.eurydice.org. DOI 10.2797/3598. Access on 09.11.2015.

8. Zoghi M, Kazemi SA and Kalani A. The Effect of Gender on Language Learning. J Nov . Appl Sci. 2013;2(s4):1124-1128.

9. OECD. The ABC of Gender Equality in Education: Aptitude, Behaviour, Confidence, PISA [Internet].2015, OECD Publishing. Available from http://dx.doi.org/10.1787/9789264229945-en. Access on 09.11.2015.

10. World Development Report 2012. Education and health: Where do gender differences really matter? Chapter3. pp.104-148. 